This paper has been published in Current Opinion in Psychology, 2017, 15, 189-194.

DOI:10.1016/j.copsyc.2017.03.012

\title{
Pairing attachment theory and social learning theory in video-feedback intervention to promote positive parenting ${ }^{1}$
}

\author{
Femmie Juffer, Marian J. Bakermans-Kranenburg, \& Marinus H. van IJzendoorn \\ Leiden University \\ Centre for Child \& Family Studies \\ Leiden, the Netherlands
}

Marian Bakermans-Kranenburg (VICI grant) and Marinus van IJzendoorn (SPINOZA prize) were supported by research awards from the Netherlands Organization for Scientific Research. Correspondence to Femmie Juffer, Leiden University, Centre for Child \& Family Studies, P.O. Box 9555, 2300 RB Leiden, the Netherlands; email address: juffer@fsw.leidenuniv.nl.

\footnotetext{
${ }^{1}$ This article is partly based on Juffer and Steele, 2014 [4] and Juffer, Bakermans-Kranenburg, and Van IJzendoorn, in press [14].
} 


\begin{abstract}
Video-feedback Intervention to promote Positive Parenting and Sensitive Discipline (VIPP$\mathrm{SD}$ ) is a social-learning and attachment-based intervention using video feedback to support sensitive parenting and at the same time setting firm limits. Empirical studies and metaanalyses have shown that sensitive parenting is the key determinant to promote secure childparent attachment relationships and that adequate parental discipline contributes to fewer behavior problems in children. Building on this evidence, VIPP-SD has been tested in various populations of at-risk parents and vulnerable children (in the age range of zero to six years), as well as in the context of child care. In twelve randomized controlled trials including 1,116 parents and caregivers, VIPP-SD proved to be effective in promoting sensitive caregiving, while positive social-emotional child outcomes were also found.
\end{abstract}




\section{Introduction}

This review focuses on Video-feedback Intervention to promote Positive Parenting and Sensitive Discipline (VIPP-SD). VIPP-SD is based on attachment theory and social learning theory, using video feedback to support sensitive parenting and at the same time setting firm limits. The use of video feedback as an indispensable feature of VIPP-SD is described and the intervention model, including themes and intervention procedure, is presented.

Empirical studies and meta-analyses have shown that sensitive parenting is the key determinant to promote secure child-parent attachment relationships and that adequate parental discipline contributes to fewer behavior problems in children. Building on this evidence, VIPP-SD has been tested in various populations of at-risk parents and vulnerable children, as well as in the context of child care. In a meta-analysis on twelve randomized controlled trials the effectiveness of VIPP-SD in promoting sensitive caregiving is examined, while positive social-emotional child outcomes are also reviewed.

\section{The use of video feedback in attachment-based interventions}

Since the formulation of attachment theory [1,2], a large number of attachment-based interventions have been designed and tested [3]. From the beginning this development has been accompanied by the use of visual media like films and videos, first to better understand attachment in children and then to support attachment security in children [4]. Films played an important role in helping to understand attachment when attachment theory was developed about half a century ago, with for example the famous black-white films of James and Joyce Robertson (e.g., A Two-year-old Goes to Hospital [5]). The role of video in helping to support attachment started later and profited from the increasing availability of small video cameras in the 1980s [4]. Video is now widely used in a large variety of interventions and home-visiting programs. In many intervention programs the method of video feedback is used: filming parent-child interactions and at a later time reviewing the videotape with the parent or caregiver.

We examined the effectiveness of attachment-based interventions in a comprehensive metaanalysis including 70 studies and 88 interventions on parental sensitivity or infant attachment [3]. Short-term, interaction-focused interventions appeared to be most successful in promoting sensitive parenting and children's attachment security. We also found that interventions with 
video feedback were more effective in improving sensitive parenting than interventions without this technique, supporting the power of the use of video for parenting interventions.

There are several reasons why video is an effective and widely used method in attachmentbased interventions [4]. First, video enables very precise observations of even subtle behaviors of children and parents. Second, an intervener can use 'Speaking for the child' by providing 'subtitles' to the child's behavior, emotions, and expressions shown on the video $[6,7]$. Parents are thus stimulated to see their child's perspective, and consequently their observational skills may improve. Accurate observation of the child's behavior is one of the crucial elements of Mary Ainsworth's [2] construct of parental sensitivity. Third, the intervener can show and reinforce positive moments of parent-child interaction, thus empowering the parent to react to the child in a prompt and adequate way - the other essential element of Ainsworth's construct of sensitivity [7]. Finally, through reviewing videos of daily interactions with their child parents may be stimulated to reflect on their parenting behavior, including the emergence of 'coercive cycles' [8], requiring limit setting.

\section{VIPP-SD: intervention model}

The use of video feedback is a key feature of Video-feedback Intervention to promote Positive Parenting and Sensitive Discipline (VIPP-SD). VIPP-SD is based on an integration of attachment theory [1,2] and social learning theory, particularly coercion theory [8]. Metaanalytic research has confirmed that securely attached children show more social competence and fewer externalizing and internalizing behavior problems than insecurely attached children $[9,10,11]$. While sensitivity is the central parenting concept in attachment theory, coercion theory emphasizes how ineffective parental discipline strategies result in increasingly difficult and challenging child behavior ('coercive cycles' [8]). Instead of rewarding negative child reactions by giving in to difficult child behavior, parents should reinforce children's positive behaviors and set rules and limits in adequate ways (see [12] for an example of an intervention study targeting challenging child behavior). In the VIPP-SD program concepts from both attachment theory and coercion theory are used during the video-feedback intervention. The program can be used without the Sensitive-Discipline component (VIPP; often used with parents of infants up to their first birthday) or with this component (VIPP-SD) when families with 'terrible twos' and older children are targeted. 
The VIPP-SD program is both standardized and individualized, meaning that interveners work from a standard protocol but attune the guidelines from the protocol to the specific parent-child dyad, resulting in individualized video feedback [7]. Each intervention visit starts with filming parent-child interaction and continues with video feedback based on the recordings of the previous visit. VIPP-SD is home-based and short-term: the interventions are implemented in the home or childcare setting in a modest number of visits, usually six sessions. VIPP-SD is implemented in the home or childcare setting, because the intervention focuses on reinforcing naturally occurring parent-child interactions in daily situations.

VIPP-SD can be used in a broad range of clinical and non-clinical families (with children in the age range of zero to six years) and in childcare settings. Adaptations in terms of observation settings and feedback have been made for optimal fit with parents or children at risk (for example children with autism), specific families (e.g., minority families), and homebased or center daycare. Interveners work with a manualized protocol, after a formal training and supervised practice. Building a trusting relationship between the parent and intervener during the intervention is of paramount importance: A relationship in which the caregiver is recognized as an 'expert' of this child and empowered with positive parenting skills and experiences.

It should be noted that the VIPP-SD program with its modest number of sessions is not and cannot be a panacea for all parental or family problems. In fact, VIPP-SD is not developed to cure parents' socio-emotional problems but to enhance the quality of parent-child interactions, even though the parent may be suffering from social or psychological issues. Therefore, dependent on the population to serve, a useful framework is to combine VIPP-SD with other treatment modalities. For example, in a study on mothers with eating disorders, the mothers not only received VIPP to support parent-child interactions during mealtime, but also a guided cognitive behavior self-help manual to address their eating problems [13]. VIPP-SD can thus be used as a stand-alone intervention to support vulnerable families or to enhance professional skills in child care, but it can also be combined with other or longer treatment.

\section{VIPP-SD themes and sessions}

Based on attachment theory $[1,2]$ themes for sensitive parenting were developed, and based on coercion theory [8] themes for sensitive discipline were formulated. In each VIPP-SD 
intervention session, one theme for sensitive parenting and one theme for sensitive discipline is highlighted (see Table 1) [7,14]. In the last two booster sessions all themes are repeated.

Table 1 Themes in the VIPP-SD program

\begin{tabular}{cll}
\hline Session & Sensitive Parenting & Sensitive Discipline \\
\hline 1. & Exploration versus attachment behavior & Inductive discipline and distraction \\
2. & 'Speaking for the child' & Positive reinforcement \\
3. & Sensitivity chain & Sensitive time-out \\
4. & Sharing emotions & Empathy for the child \\
5. & Booster session & Booster session \\
6. & Booster session & Booster session \\
\hline
\end{tabular}

For sensitive parenting the structure of the VIPP-SD program closely follows the two main components of Ainsworth's [2] definition of sensitivity: (1) accurate perception and interpretation of the child's signals and behavior, and (2) prompt and adequate reactions to these signals. In the first and second intervention session parents are encouraged to accurately observe and interpret their child's behavior on the recorded video fragments. Therefore, the intervenor uses the 'Speaking for the child' technique (see before) and kindly invites the parent to participate in this process. During the third and fourth session the video feedback also focuses on the second part of Ainsworth's definition and parents are supported to respond to their child's behavior, emotions and expressions in a sensitive way.

For sensitive discipline, relevant themes are highlighted during the intervention sessions (see Table 1). For example, in the first intervention session parents are encouraged to use inductive discipline by explaining to the child the reason for their commands and limits, thus helping the child to internalize parental rules and develop empathy with other people's interests. In this session parents are also suggested to use distraction as a useful technique to support child compliance by suggesting alternatives or postponing attractive activities to a later moment.

\section{Effectiveness of VIPP-SD}

The effectiveness of VIPP-SD was examined in twelve randomized controlled trials so far, in various samples of children at risk, parents at risk or in special situations, and in childcare 
settings [14]. All studies used the VIPP-SD program (or the slightly modified version for specific groups), most of them with the Sensitive Discipline component. The studies with children at risk included adopted children [15], children at risk of externalizing problem behavior [16], children with autism and infants at risk of autism [17-19]. The studies with parents at risk or in special situations included insecure parents [20,21] (for a related exploratory study see [22]), parents with eating disorders [13], insensitive parents [23], maltreating parents [24], ethnic minority parents [25], and highly deprived, high-risk parents in a poverty context $[26,27]$.

To support the sensitivity and firm limit setting of caregivers in group settings such as childcare centers, VIPP-SD was adapted from a dyadic program including one parent and one child into a program focusing on one caregiver and several children. One study included caregivers in home-based child care [28] and another study included caregivers in child-care centers [29].

We meta-analyzed the results of the twelve randomized controlled trials (including 1,116 parents and caregivers) testing the effectiveness of VIPP-SD on sensitive parenting. The meta-analysis showed a combined effect size of $d=0.47$ in a homogeneous set of outcomes [14]. This implies that sensitivity increased with about half a standard deviation as a result of participation in the VIPP-SD program. The individual and combined effect sizes are illustrated in Figure 1. 


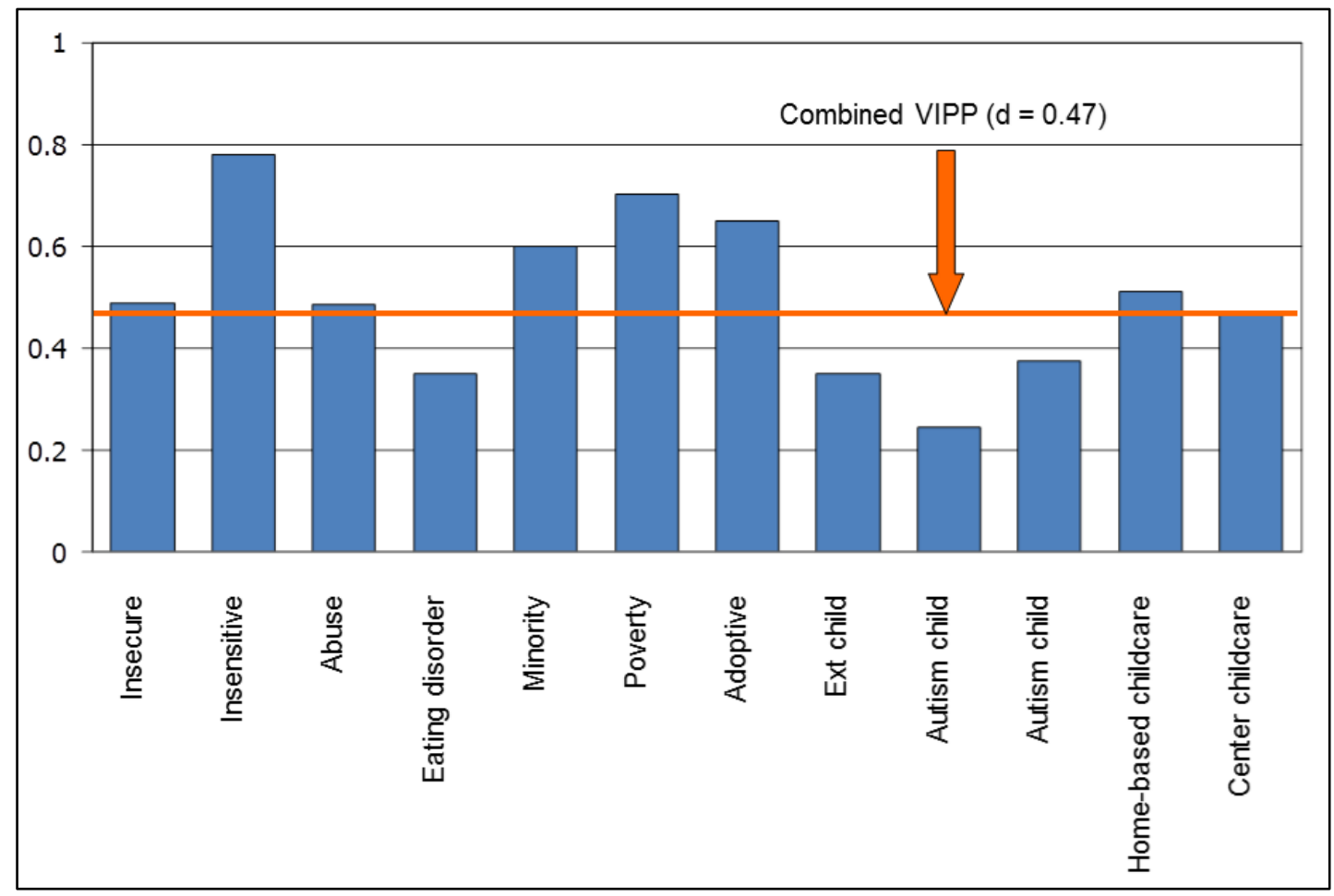

Figure 1 Individual and combined effect sizes for sensitivity of the twelve VIPP-SD randomized controlled trials (total $N=1,116$ ). Source: Juffer, Bakermans-Kranenburg, \& Van IJzendoorn, in press [14].

In all twelve studies included in the meta-analysis a significant increase in sensitive caregiving was found, reflecting the major aim of VIPP, that is: promoting positive parenting. Apart from this outcome, several positive results were found on other (related) parenting and child outcomes (see Figure 2 and see [14] for more details). The combined effect size for improved child outcomes was $d=0.37 ; k=8, N=721$ ) in a homogeneous set of outcomes. Four studies measured effects on attachment; the combined effect size for attachment was $d=0.36$. The seven studies that assessed child problem behavior showed a combined effect size of $d=0.26$ for reduced child problem behavior. Moreover, the effects remained of similar strength over time: Follow-up studies revealed a combined effect size of $d=0.25$. The VIPP thus promoted long-term improvement in child outcomes that are probably related to the effects on positive parenting. 


\section{Outcomes of VIPP}
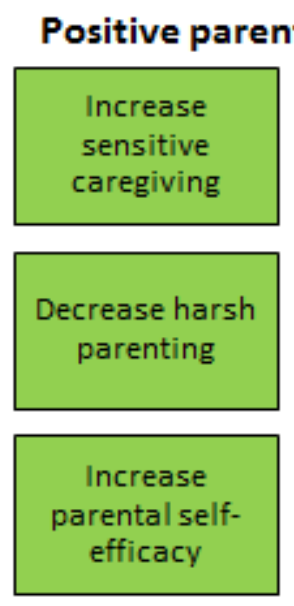
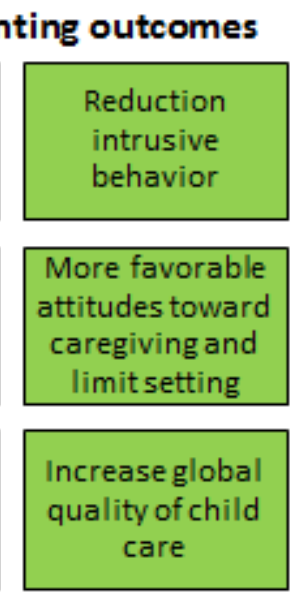

Positive child outcomes
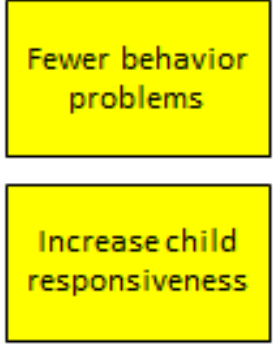

Reduction daily cortisol in infants with DRD4 7 repeat allele
Lower rates

disorganized

attachment

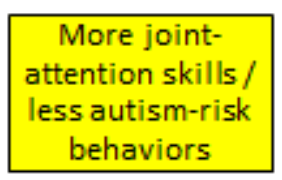

Greater autonomy during mealtime

Figure 2 Positive parenting and child outcomes after the intervention, reported in the twelve VIPP-SD randomized controlled trials (total $N=1,116$ ).

\section{Future directions}

Convergent with a similar trend in attachment research, the first focus of VIPP-SD has been on mother-child dyads. VIPP-SD was implemented in families struggling with specific risks or problems in the parents or in their children [14]. VIPP-SD was also adapted for substitute parents, that is, adoptive and foster mothers and caregivers in childcare. The next step is to implement VIPP-SD in fathers (for a pilot study see [30]) and in couples. Future studies may also show when the limits of its effectiveness will be reached. Does VIPP-SD work for parents with learning disabilities [31], for children exposed to severe early adversity, or in extremely deprived settings such as orphanages?

Another important question is whether VIPP-SD is equally effective for different types of children and parents. There is accumulating evidence for differential susceptibility, also in the context of interventions $[32,33]$. This points to the hidden efficacy of interventions: In subgroups the intervention is (much) more effective than the overall effect size suggests. For VIPP-SD, the largest effects have been found for children with difficult temperaments and children with a specific variant of the dopamine D4 receptor gene. These children were most 
susceptible to changes in their caregiving environment: Temperamentally difficult children showed more secure attachment behavior after a change for the better in their mothers' sensitivity [20], and children with the DRD4-7R allele showed the strongest decrease in externalizing behavior and daily cortisol production after participation of their mothers in the VIPP-SD program [34,35]. Their mothers' increase in the use of sensitive discipline mediated this effect. An important issue for future studies is to adapt intervention efforts in a way that provides optimal 'susceptibility fit' with the recipients of the VIPP-SD program.

Because of its relatively short duration VIPP-SD might be used at a diagnostic tool in the process of decision making about out-of-home placement of children who run the risk of becoming maltreated by their parents or who already have undergone some abusive parenting. Valid predictive diagnosis about parental openness to support and feedback might be based on their participation in a VIPP-SD training, in which their progress in terms of sensitive parenting and limit setting is carefully monitored. In fact, in such a dynamic diagnostic approach, treatment and diagnosis go hand in hand to allow for an evidence-based therapeutic as well as legal decision about the future of the child and the parents.

A crucial question about the effectiveness of interventions such as the VIPP-SD program is its 'embodiment' in parents and children, thus affecting their relationship not only in the shortbut also in the long-term [14]. We found positive changes in cortisol production in toddlers participating in VIPP-SD even two years after the intervention [34]. This hormonal change might be connected to a cascade of neurobiological changes as a consequence of improved parenting. To trace other links in this cascade, from epigenetic changes influencing the expression of genes to changes in neural connectivity in the brain, is a major challenge in the search for mechanisms of effective attachment-based interventions. 


\section{References and recommended reading}

Publications of particular interest have been highlighted as:

* of interest

** of special interest

1. Bowlby, J. (1982). Attachment and loss (Vol. 1). Attachment (2nd ed.). New York: Basic Books.

2. Ainsworth, M.D.S., Blehar, M.C., Waters, E., \& Wall, S. (1978). Patterns of attachment. A psychological study of the Strange Situation. Hillsdale, N.J.: Lawrence Erlbaum.

3. **Bakermans-Kranenburg, M.J., Van IJzendoorn, M.H., \& Juffer, F. (2003). Less is more: Meta-analysis of sensitivity and attachment interventions in early childhood. Psychological Bulletin, 129, 195-215.

This meta-analysis examined 70 studies in families with and without multiple problems, producing 88 intervention effects on parental sensitivity and/or infant attachment. The most effective interventions used a moderate number of studies and a clear-cut interactional focus. Interventions that were more effective in enhancing sensititivity were also more effective in promoting secure attachment relationships, which confirms the causal role of sensitive parenting in shaping children's attachment security.

4. Juffer, F., \& Steele, M. (2014). What words cannot say: The telling story of video in attachment-based interventions. Attachment \& Human Development, 16(4), 307-314. 5. Robertson, J. \& Robertson, J. (1989). Separation and the very young. London: Free Association Books.

6. Carter, S.L., Osofsky, J.D., \& Hann, D.M. (1991). Speaking for the baby: A therapeutic intervention with adolescent mothers and their infants. Infant Mental Health Journal, 12, 291301.

7. *Juffer, F., Bakermans-Kranenburg, M.J., \& Van IJzendoorn, M.H. (Eds.) (2008). Promoting positive parenting: An attachment-based intervention. New York: Taylor \& Francis.

This volume describes the development and features of the Video-feedback Intervention to promote Positive Parenting and Sensitive Discipline (VIPP-SD) program, elaborating on the theoretical background as well as on the practical characteristics of the intervention procedure. In VIPP-SD a combination of attachment theory and social learning theory (in particular, coercion theory) is translated into an 
intervention program aimed at supporting sensitive parenting and firm discipline. The volume explains the technique of video-feedback and present findings from several VIPP-SD studies (for example, in adoptive families and in families with toddlers with externalizing problem behavior).

8. Patterson, G.R. (1982). Coercive family process. Eugene, OR: Castilia.

9. Groh, A. M., Fearon, R. P., Bakermans-Kranenburg, M. J., Van IJzendoorn, M. H., Steele,

R. D., \& Roisman, G. I. (2014). The significance of attachment security for children's social competence with peers: a meta-analytic study. Attachment \& Human Development, 16(2), 103-136. doi: 10.1080/14616734.2014.883636

10. *Fearon, R. P., Bakermans-Kranenburg, M. J., van IJzendoorn, M. H., Lapsley, A. M., \& Roisman, G. I. (2010). The significance of insecure attachment and disorganization in the development of children's externalizing behavior: A meta-analytic study. Child Development, 81(2), 435-456.

This meta-analysis, including 69 samples, examined the association between children's insecure attachment and their externalizing behavior problems. A significant relation between insecurity and externalizing problems was found, with larger effects for boys, clinical samples, and studies using observation-based outcome assessments.

11. Groh, A. M., Roisman, G. I., van IJzendoorn, M. H., Bakermans-Kranenburg, M. J., \& Fearon, R. P. (2012). The significance of insecure and disorganized attachment for children's internalizing symptoms: A meta-analytic study. Child Development, 83(2), 591-610. doi: 10.1111/j.1467-8624.2011.01711.x

12. Scott, S., Briskman, J., \& O'Connor, T. G. (2014). Early prevention of antisocial personality: Long-term follow-up of two randomized controlled trials comparing indicated and selective approaches. American Journal of Psychiatry, 171(6), 649-657. doi:

10.1176/appi.ajp.2014.13050697

13. Stein, A., Woolley, H., Senior, R., Hertzmann, L., Lovel, M., Lee, J., ... Fairburn, C.G. 
(2006). Treating disturbances in the relationship between mothers with bulimic eating disorders and their infants: a randomized, controlled trial of video feedback. The American Journal of Psychiatry, 163, 899-906.

14. *Juffer, F., Bakermans-Kranenburg, M.J., \& Van IJzendoorn, M.H. (in press). Videofeedback Intervention to promote Positive Parenting and Sensitive Discipline (VIPP-SD): Development and meta-analytical evidence of its effectiveness. In H. Steele \& M. Steele (Eds.), Handbook of attachment-based interventions. New York: Guilford.

This chapter presents an overview of the current research on the VIPP-SD program, including a narrative review and a meta-analysis of 12 randomized controlled trials testing the effectiveness of VIPP-SD on sensitive parenting.

15. Juffer, F., Bakermans-Kranenburg, M.J., \& Van IJzendoorn, M.H. (2005). The importance of parenting in the development of disorganized attachment: Evidence from a preventive intervention study in adoptive families. Journal of Child Psychology and Psychiatry, 46, 263274.

16. Van Zeijl, J., Mesman, J., Van IJzendoorn, M.H., Bakermans-Kranenburg, M.J., Juffer, F., Stolk, M.N., ... Alink, L.R.A. (2006). Attachment-based intervention for enhancing sensitive discipline in mothers of one- to three-year-old children at risk for externalizing behavior problems. Journal of Consulting and Clinical Psychology, 74(6), 994-1005.

17. Poslawsky, I.E., Naber, F.B.A., Bakermans-Kranenburg, M.J., De Jonge, M.V., Van Engeland, H., \& Van IJzendoorn, M.H. (2014). Development of a Video-feedback Intervention to promote Positive Parenting for Children with Autism (VIPP-AUTI). Attachment \& Human Development, 16(4), 343-355.

18. Poslawsky, I. E., Naber, F. B. A., Bakermans-Kranenburg, M. J., Van Daalen, E., Van Engeland, H., \& Van IJzendoorn, M. H. (2015). Video-feedback Intervention to promote Positive Parenting adapted to Autism (VIPP-AUTI): A randomized controlled trial. Autism, 19(5), 588-603.

19. **Green, J., Charman, T., Pickles, A., Wan, M.W., Elsabbagh, M., Slonims, V., . . the BASIS team. (2015). Parent-mediated intervention versus no intervention for infants at high risk of autism: a parallel, single-blind, randomised trial. The Lancet, 2, 133-140.

This study presents a unique randomized controlled trial to test the VIPP program adapted to families with children at risk of autism (iBASIS-VIPP). The intervention increased the infants' attentiveness to the parent and reduced their autism-risk behaviors, while it also resulted in increased parental non-directiveness and parentreported adaptive functioning of the infant. 
20. Klein Velderman, M. Bakermans-Kranenburg, M.J., Juffer, F., \& Van IJzendoorn, M.H. (2006). Effects of attachment-based interventions on maternal sensitivity and infant attachment: Differential susceptibility of highly reactive infants. Journal of Family Psychology, 20, 266-274.

21. Klein Velderman, M., Bakermans-Kranenburg, M.J., Juffer, F., Van IJzendoorn, M.H., Mangelsdorf, S.C., \& Zevalkink, J. (2006). Preventing preschool externalizing behavior problems through video-feedback intervention in infancy. Infant Mental Health Journal, 27(5), 466-493.

22. Cassibba, R., Castoro, G., Costantino, E., Sette, G., \& Van IJzendoorn, M.H. (2015). Enhancing maternal sensitivity and infant attachment security with video feedback: An exploratory study in Italy. Infant Mental Health Journal, 36(1), 53-61.

23. Kalinauskiene, L., Cekuoliene, D., Van IJzendoorn, M.H., Bakermans-Kranenburg, M.J., Juffer, F., \& Kusakovskaja, I. (2009). Supporting insensitive mothers: The Vilnius randomized control trial of video feedback intervention to promote maternal sensitivity and infant attachment. Child: Care, Health \& Development, 35, 613-623.

24. **Moss, E., Dubois-Comtois, K., Cyr, C., Tarabulsy, G.M., St-Laurent, D., \& Bernier, A. (2011). Efficacy of a home-visiting intervention aimed at improving maternal sensitivity, child attachment, and behavioral outcomes for maltreated children: A randomized control trial. Development and Psychopathology, 23(1), 195-210.

This study examined the effectiveness of a program based on VIPP in primary caregivers reported for maltreatment and their children under five. In these vulnerable families the intervention resulted in enhanced parental sensitivity. Also, a greater proportion of insecure children in the intervention group became secure in comparison with the control group, while a greater proportion of disorganized children in the intervention group became organized in comparison with the control group.

25. Yagmur, S., Mesman, J., Malda, M., Bakermans-Kranenburg, M.J., \& Ekmekci, H. (2014). Video-feedback intervention increases sensitive parenting in ethnic minority mothers: a randomized control trial. Attachment \& Human Development, 16(4), 371-386.

26. *Negrao, M., Pereira, M., Soares, I., \& Mesman, J. (2014). Enhancing positive parentchild interactions and family functioning in a poverty sample: a randomized control trial. Attachment \& Human Development, 16(4), 315-328.

This study (and see also reference 23) examined the effectiveness of VIPP-SD in poor families of toddlers screened for professional's concerns about the child's caregiving environment. The intervention resulted in an increase of sensitive parenting and a 
decrease of harsh discipline.

27. Pereira, M., Negrão, M., Soares, I., \& Mesman, J. (2014). Decreasing harsh discipline in mothers at risk for maltreatment: A randomized control trial. Infant Mental Health Journal, 35(6), 604-613.

28. *Groeneveld, M.G., Vermeer, H.J., Van IJzendoorn, M.H., \& Linting, M. (2011).

Enhancing home-based child care quality through video-feedback intervention: A randomized controlled trial. Journal of Family Psychology, 25(1), 86-96.

This study tested VIPP-SD in a randomized controlled trial in home-based child care.

The intervention enhanced global quality, indicating quality and quantity of stimulation and support available to a child in the child care environment. The caregivers in the intervention group also showed a more positive attitude toward sensitive caregiving and limit setting at the posttest than the caregivers in the control group.

29. Werner, C., Vermeer, H.J., Linting, M., \& Van IJzendoorn, M.H. (2016). Video-feedback intervention in center-based child care: A randomized controlled trial. Leiden, the Netherlands: Leiden University.

30. Lawrence, P.J., Davies, B., \& Ramchandani, P.G. (2013). Using video feedback to improve early father-infant interaction: A pilot study. Clinical Child Psychology and Psychiatry, 18(1), 61-71.

31. Hodes, M.W., Meppelder, H.M., Schuengel, C., \& Kef, S. (2014). Tailoring a videofeedback intervention for sensitive discipline to parents with intellectual disabilities: a process evaluation. Attachment \& Human Development, 16(4), 387-401.

32. Van IJzendoorn, M.H. \& Bakermans-Kranenburg, M.J. (2012). Differential susceptibility experiments: Going beyond correlational evidence: Comment on beyond mental health, differential susceptibility articles. Developmental Psychology, 48, 769-774.

33. **Bakermans-Kranenburg, M.J. \& Van IJzendoorn, M.H. (2015).The hidden efficacy of interventions: Gene x Environment experiments from a differential susceptibility perspective. Annual Review of Psychology.

This review sheds light on implications of the concept of differential susceptibility for intervention programs. The efficacy of interventions might be underestimated or even go undetected when it is hidden in gene-by-environment $(\mathrm{G} \times \mathrm{E})$ interactions. The differential susceptibility model predicts that carriers of risk genotypes profit most from interventions changing the environment for the better. Meta-analytical evidence for the differential susceptibility model is presented showing that intervention effects 
were stronger in the susceptible genotypes than in the non-susceptible genotypes.

34. Bakermans-Kranenburg, M.J., Van IJzendoorn, M.H., Mesman, J., Alink,

L.R.A., \& Juffer, F. (2008). Effects of an attachment-based intervention on daily cortisol moderated by dopamine receptor D4: A randomized control trial on 1- to 3-year-olds screened for externalizing behavior. Development and Psychopathology, 20, 805-820.

35. Bakermans-Kranenburg, M.J., Van IJzendoorn, M.H., Pijlman, F.T.A., Mesman, J., \& Juffer, F. (2008). Differential susceptibility to intervention: Dopamine D4 Receptor Polymorphism (DRD4 VNTR) moderates effects on toddlers' externalizing behavior in a randomized control trial. Developmental Psychology, 44, 293-300.* 